\title{
Material analysis and characterization of working electrodes of dye-sensitized solar cells
}

\author{
Yeong-Lin Lai ${ }^{1, *}$, Hung-Ru $\mathrm{Hsu}^{2}$, Yeong-Kang Lai ${ }^{3}$, Yung-Hua Chou ${ }^{1}$, Nai-Kun $\mathrm{Hsu}^{1}$, and \\ Chun-Yi Zheng ${ }^{1}$ \\ ${ }^{1}$ Department of Mechatronics Engineering, National Changhua University of Education, Changhua \\ 50007, Taiwan \\ ${ }^{2}$ Green Energy and Environment Research Laboratories, Industrial Technology Research Institute, \\ Hsinchu 31040, Taiwan \\ ${ }^{3}$ Department of Electrical Engineering, National Chung Hsing University, Taichung 40227, Taiwan
}

\begin{abstract}
The aim of this paper is to demonstrate the influence of the $\mathrm{TiO}_{2}$ with different sintered time regarding the performance of photovoltaic characteristics of DSSCs. A layer of $\mathrm{TiO}_{2}$ with a thickness of $\sim 8-10 \mu \mathrm{m}$ and an area of $0.25 \mathrm{~cm}^{2}$ was prepared by depositing $\mathrm{TiO}_{2}$ nanoparticles paste onto a fluorine-doped tin oxide (FTO) sbustrate by doctor blade technique, followed by sinterring at $450^{\circ} \mathrm{C}$ with 4 differennt sintering times: $10 \mathrm{~min}, 20 \mathrm{~min}, 30 \mathrm{~min}$, and $40 \mathrm{~min}$. The Pt solution was dripped on FTO substrate works as counter electrode. SEM, XRD and I-V curve were conducted for the material analysis. The photovoltaic characteristics were measured under AM 1.5 sunlight simulator. The results reveal that the different sintered time of $\mathrm{TiO}_{2}$ working electrode did affect the photovoltaic conversion efficiency. In conclusion, $\mathrm{TiO}_{2}$ sintered for 30 min yields the highest power conversion efficiency of $6.273 \%$.
\end{abstract}

\section{Introduction}

The needs for alternative energy has become a great concern due to the growing energy demand. Solar energy resource is a rich and clean renewable energy and has attracted great attention of researchers in the world. According to the BP Statistical Review of World Energey, it revealed that the reserves/production ratio for oil, natural gas and coal was 50.6 years, 52.5 years, and 153 years, respectively in 2017. [1-2]. Among all of these materials, dye-sensitized solar cells (DSSCs) is one of the most prospective materials for photovoltaic solar cell devices $[1,3]$. The advantages of DSSCs including easy fabrication, cost-effectiveness, excellent low light performance, highly flexible, and lightweight $[1,3]$.

A conventional DSSCs consists three main components: a mesoporous nanocrystalline $\mathrm{TiO}_{2}$ anode which sensitized with light-absorbing dye molecules, a counter electrode (CE) which collects electronsand catalyze the redox couple regeneration, and a liquid electrolyte which comprising an iodide/triiodide $\left(\mathrm{I}^{-} / \mathrm{I}_{3}^{-}\right)$redox couple between two electrodes[3-4].

A layer of $\mathrm{TiO}_{2}$ with a thickness of $\sim 8-10 \mu \mathrm{m}$ and area of $0.25 \mathrm{~cm}^{2}$ was usually prepared by depositing $\mathrm{TiO}_{2}$ nanoparticles paste onto FTO by doctor blade technique,

*Corresponding author: yllai@cc.ncue.edu.tw 
followed by sinterring at $450^{\circ} \mathrm{C}$ for $30 \mathrm{~min}$. The sintered $\mathrm{TiO}_{2}$ FTO was then immersing into N719 dye solutionfor dye absorption[5-6].

This paper discusses the effects on differennt annealing times of $\mathrm{TiO}_{2}$ nanoparticles, in order to find out the best quality of working electrode.

\section{Experimental}

The main components of DSSCs are fluorine-doped tin oxide (FTO) conductive glass substrate, a $\mathrm{TiO}_{2}$ film as photoanode, and a dye electrolyte and a counter electrode. The three components were stacked like a sandwich which is shown in Figure 1.

\subsection{Fabrication of photoanode}

A layer of $\mathrm{TiO}_{2}$ with a thickness of $\sim 8-10 \mu \mathrm{m}$ and area of $0.25 \mathrm{~cm}^{2}$ was prepared by depositing $\mathrm{TiO}_{2}$ nanoparticles paste onto FTO sbustrate by doctor blade technique, shown in Figure 2.

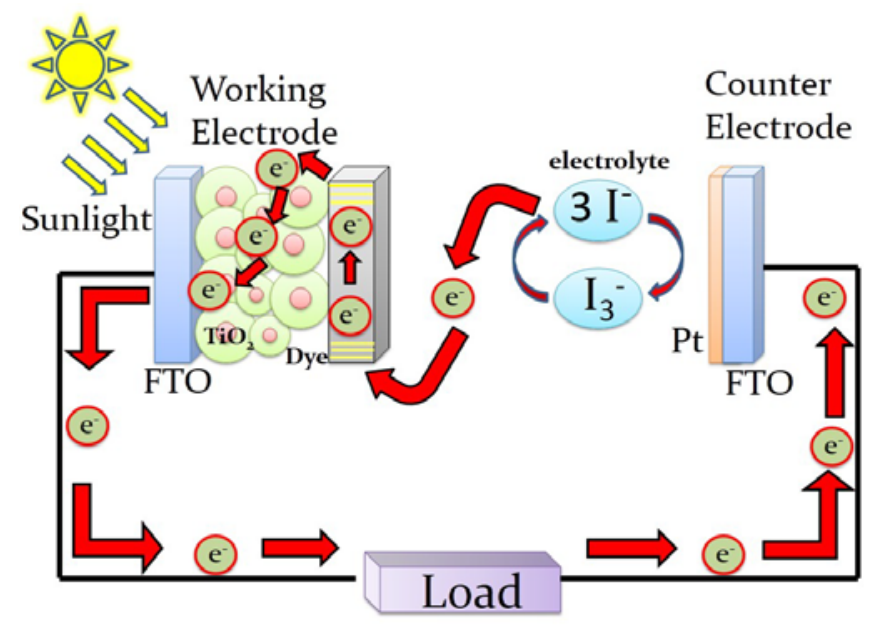

Fig. 1. The configuration of DSSCs.

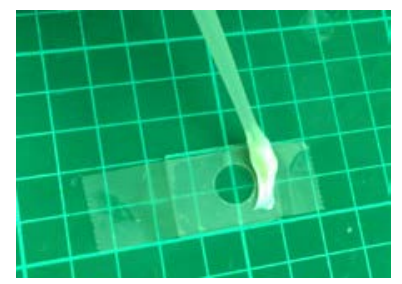

Fig. 2. Depositing $\mathrm{TiO}_{2}$ nanoparticles paste onto FTO sbustrate.

A piece of transparent tape with $1 \mathrm{~cm}$ of adiameter area was cut off and pasted on the FTO substrate. The $\mathrm{TiO}_{2}$ film was then depositing on the FTO substrate by doctor blade technique, followed by sinterring at $450^{\circ} \mathrm{C}$. These four different sintering time samples were indicated by $\mathrm{A}, \mathrm{B}, \mathrm{C}$, and $\mathrm{D}$, which corresepond to four differennt sintering time conditions, $10 \mathrm{~min}, 20 \mathrm{~min}, 30 \mathrm{~min}$, and $40 \mathrm{~min}$, repectively. The fabricated $\mathrm{TiO}_{2}$ working 
electrode is shown in Figure 3. It was then soaked in the dye solution for 24 hours at room temperature and subsequently carefully rinsed with ethanol to remove unadsorbed dye.

\subsection{Fabrication of counter electrode}

The main material for the fabrication of counter electrode (CE) was platium (Pt) by using spin coating method.

The Pt solution was dripped on FTO substrate and then placed on a spin coater machine with a spin speed of $500 \mathrm{rpm}$ for $90 \mathrm{~s}$ in order to be evenly coated on FTO stubstrate. The fabricated Pt counter electrode is demonstrated in Figure 4.

\subsection{Preparation of dyes}

Acetonitrile, tert-Butyl alcohol (TBA) and N719 dye powder were the materials to prepare for the dye. Acetonitrile and TBA were mixed with the porpotion of 1:1 and the dye concentration was $5 \times 10^{-4} \mathrm{~mol} / \mathrm{L}$. The prepared $\mathrm{TiO}_{2}$ photoanode was then soaked in the dye solution for 24 hours at room temperature.

\subsection{Preparation of electrolyte}

The chemicals used to prepare the electrolyte including $0.5 \mathrm{M}$ tert-butylpyridine, $0.005 \mathrm{M}$ iodine $\left(\mathrm{I}_{2}\right), 0.6 \mathrm{M}$ 1,2-dimethyl-3-propylimidazolium iodide, and $0.1 \mathrm{M}$ lithium iodide (LiI). The above chemicals were all mixed with acetonitrile.

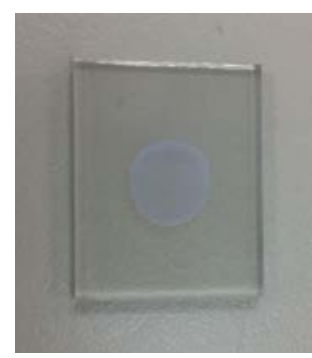

Fig. 3. Fabricated $\mathrm{TiO}_{2}$ film working electrode.

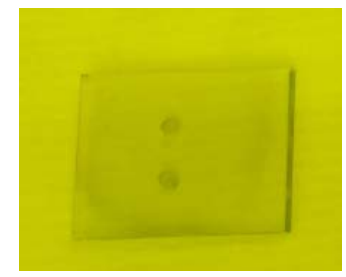

Fig. 4. Fabricated Pt counter electrode. 


\subsection{Assembly of DSSCs}

The DSSCs components were assembled started with applying a membrance (Surlyn) with an area of $1.5 \mathrm{~cm} \times 1.5 \mathrm{~cm}$ and a thickness of $60 \mu \mathrm{m}$ on $\mathrm{TiO}_{2}$ working electrode. A area with idameter of $1 \mathrm{~cm}$ was cut off in order to expose the $\mathrm{TiO}_{2}$ layer. The counter electrode was aligned and assembled with the membrance. The components were sealed together by heat press sealing maching with temperature of $145^{\circ} \mathrm{C}$ and $1.5 \mathrm{~kg} / \mathrm{mm}^{2}$ presure. The electrolyte was injected to the drilled hole of counter electrode and sealed with a $3 \mathrm{M}$ transparent tape. An assembled DSSCs device was shown in Figure 5.

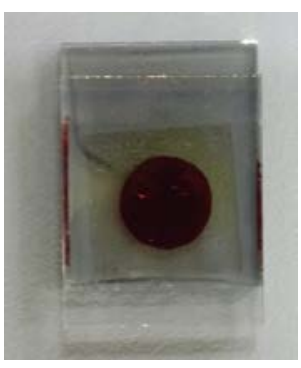

Fig. 5. Fabricated DSSCs.

\section{Results and Discussion}

\subsection{SEM analysis}

Figure 6 shows the SEM (Scanning Electron Microscopy) images of surface morphology of $\mathrm{TiO}_{2}$ sintered at $450^{\circ} \mathrm{C}$ with different time (a) $10 \mathrm{~min}$ (b) $20 \mathrm{~min}$ (c) $30 \mathrm{~min}$ (d) $40 \mathrm{~min}$. The uniformity, thickness, porosity, and grain size of $\mathrm{TiO}_{2}$ were observed through SEM. The result indicates that the adhesion of $\mathrm{TiO}_{2}$ on FTO does not change with different sintered times. In addition, the surfaces of $\mathrm{TiO}_{2}$ were coral shape and without serious cracking which helps dye absorption.

\subsection{XRD analysis}

$\mathrm{XRD}$ analysis was conducted and shown in Figure 7. It was found that $\mathrm{TiO}_{2}$ appears to be anatase phase crystals with different sintered time. However, the diffraction peak did not increase significantly as sintered time increased. It results in the best anatase phase crystals and diffraction peak under 20 and 30 min of sintered time. 


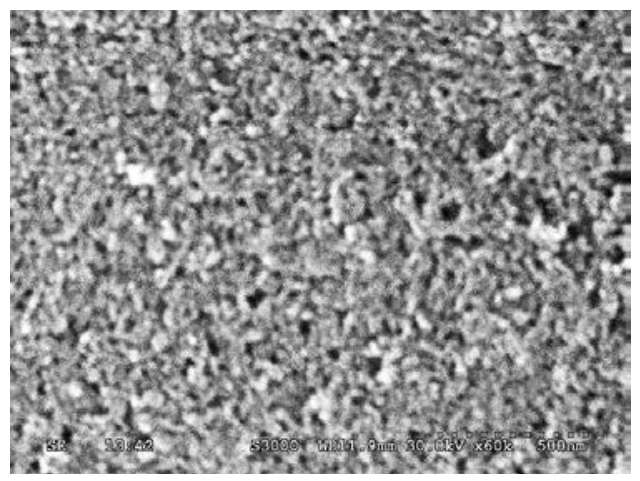

(a) $10 \min (30.0 \mathrm{kV}, \times 60 \mathrm{k})$

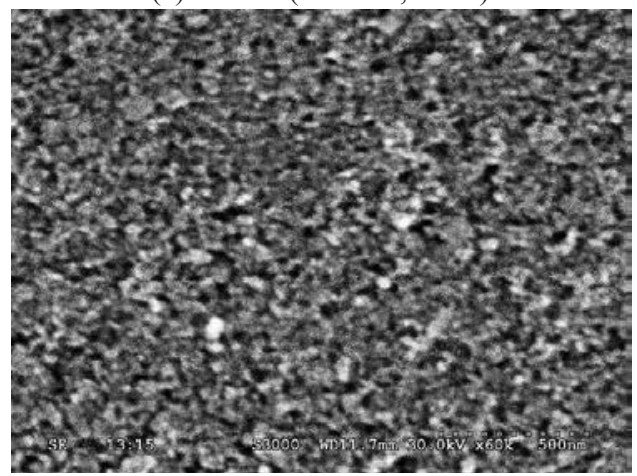

(c) $30 \min (30.0 \mathrm{kV}, \times 60 \mathrm{k})$

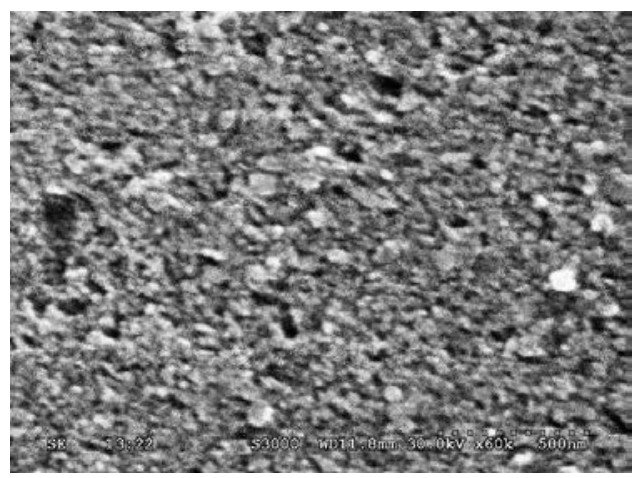

(b) $20 \min (30.0 \mathrm{kV}, \times 60 \mathrm{k})$

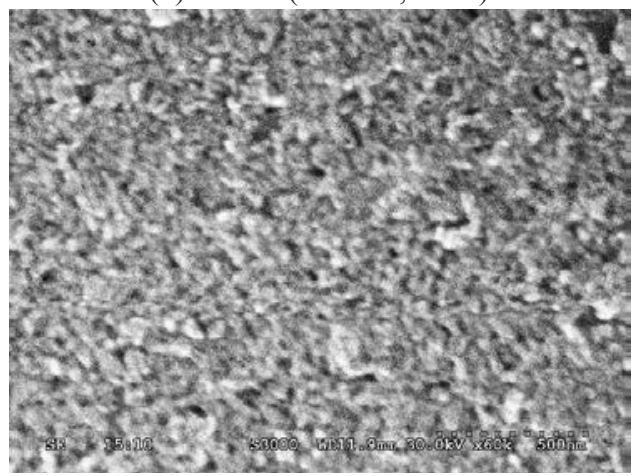

(d) $40 \min (30.0 \mathrm{kV}, \times 60 \mathrm{k})$

Fig. 6. Top SEM images of $\mathrm{TiO}_{2}$ sintered at $450^{\circ} \mathrm{C}$ with different time (a) $10 \mathrm{~min}$ (b) $20 \mathrm{~min}$ (c) $30 \mathrm{~min}$ (d) $40 \mathrm{~min}$.

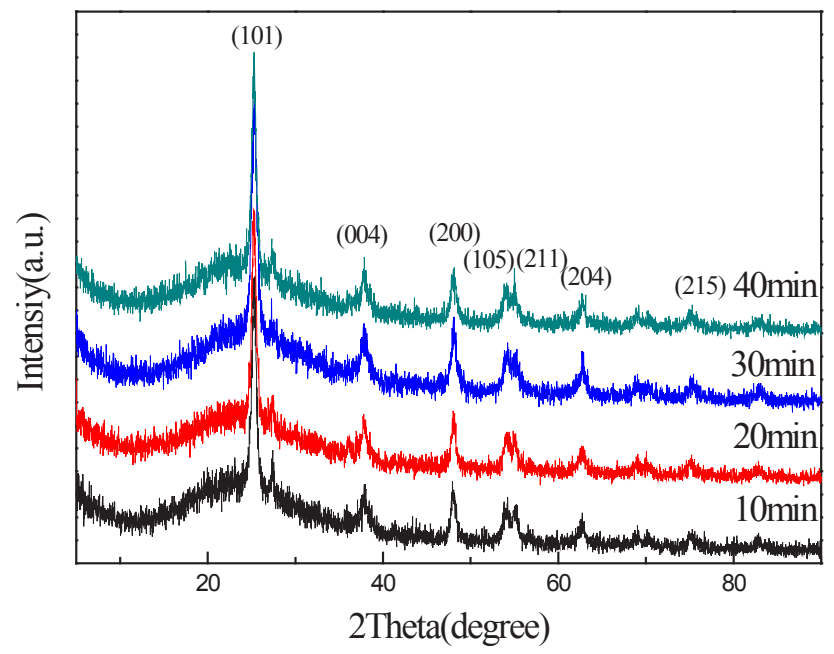

Fig. 7. XRD pattern of $\mathrm{TiO}_{2}$ with different sintered times. 


\subsection{Measurement of photovoltaic characteristics of the DSSCs}

The photovoltaic characteristics of the DSSCs were measured and shown in Figure 8. The characteristics including open-circuited voltage $\left(\mathrm{V}_{\mathrm{oc}}\right)$, short-circuited current density $\left(\mathrm{J}_{\mathrm{sc}}\right)$, fill factor (FF), and photovoltaic conversion efficiency. The results with different parameters are listed in Table 1 . The $\mathrm{J}_{\mathrm{sc}}$ of the DSSCs with the $\mathrm{TiO}_{2}$ working electrode fabricated under condition A, B, C, and D is 16.182, 16.284, 16.734, $16.423 \mathrm{~mA} / \mathrm{cm}^{2}$, respectively. The photoelectric conversion efficiency is $5.885 \%, 6.010 \%, 6.273 \%$, and $5.634 \%$, respectively.

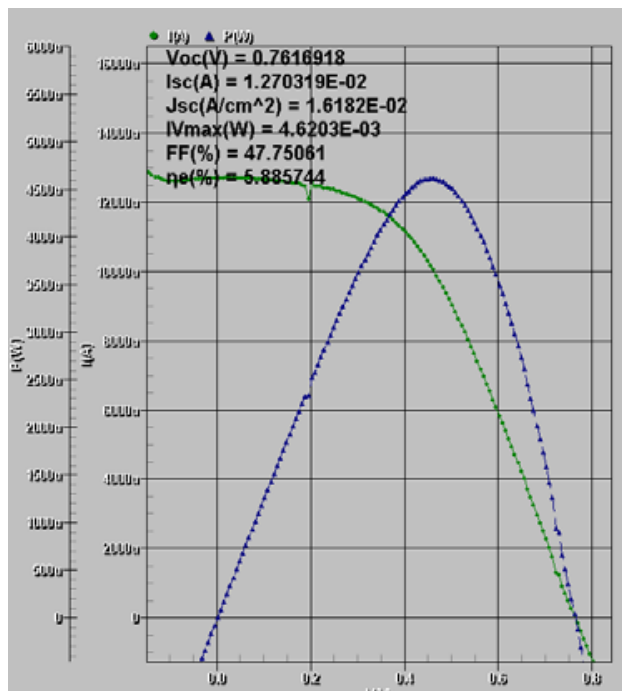

(a) $450^{\circ} \mathrm{C}, 10 \mathrm{~min}$

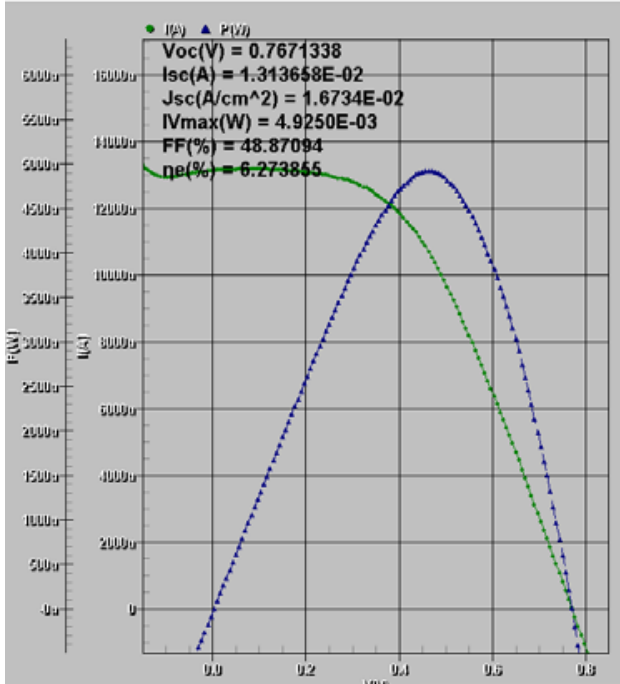

(c) $450^{\circ} \mathrm{C}, 30 \mathrm{~min}$

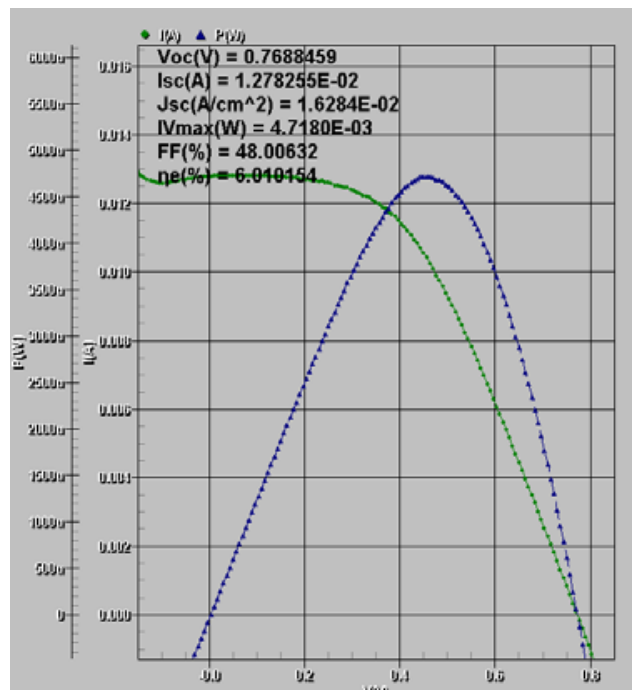

(b) $450^{\circ} \mathrm{C}, 20 \mathrm{~min}$

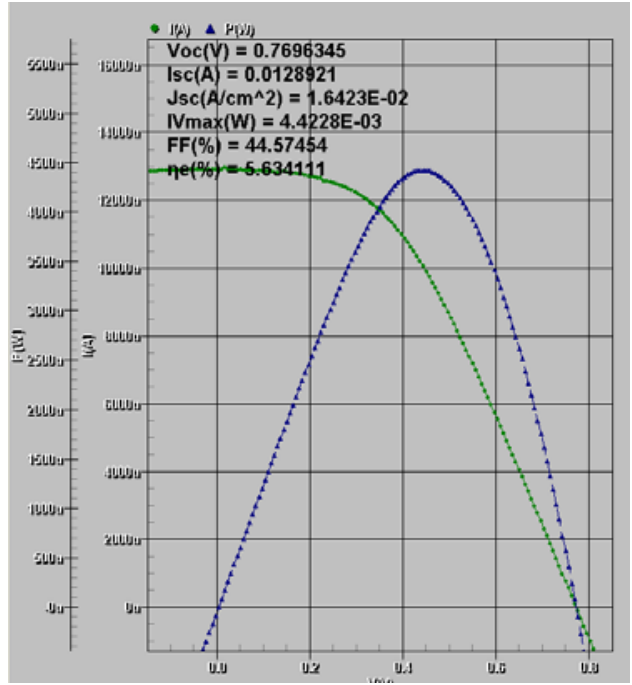

(d) $450^{\circ} \mathrm{C}, 40 \mathrm{~min}$

Fig. 8. The measurement of photovoltaic characteristics of the DSSCs with the $\mathrm{TiO}_{2}$ working electrodes. (a) $450^{\circ} \mathrm{C}, 10 \mathrm{~min}$ (b) $450^{\circ} \mathrm{C}, 20 \mathrm{~min}$ (c) $450^{\circ} \mathrm{C}, 30 \mathrm{~min}$ (d) $450^{\circ} \mathrm{C}, 40 \mathrm{~min}$. 
Table 1. The photovoltaic characteristics of the DSSCs with the $\mathrm{TiO}_{2}$ working electrodes.

\begin{tabular}{|c|c|c|c|c|}
\hline Time & $\mathbf{V}_{\text {oc }}(\mathbf{V})$ & $\mathbf{J}_{\mathbf{s c}}\left(\mathbf{m A} / \mathbf{c m}^{\mathbf{2}}\right)$ & $\mathbf{F F}(\mathbf{\%})$ & Efficiency (\%) \\
\hline $10 \mathrm{~min}$ & 0.761 & 16.182 & 47.750 & 5.885 \\
\hline $20 \mathrm{~min}$ & 0.768 & 16.284 & 48.006 & 6.010 \\
\hline $30 \mathrm{~min}$ & 0.767 & 16.734 & 48.870 & 6.273 \\
\hline $40 \mathrm{~min}$ & 0.769 & 16.423 & 44.574 & 5.634 \\
\hline
\end{tabular}

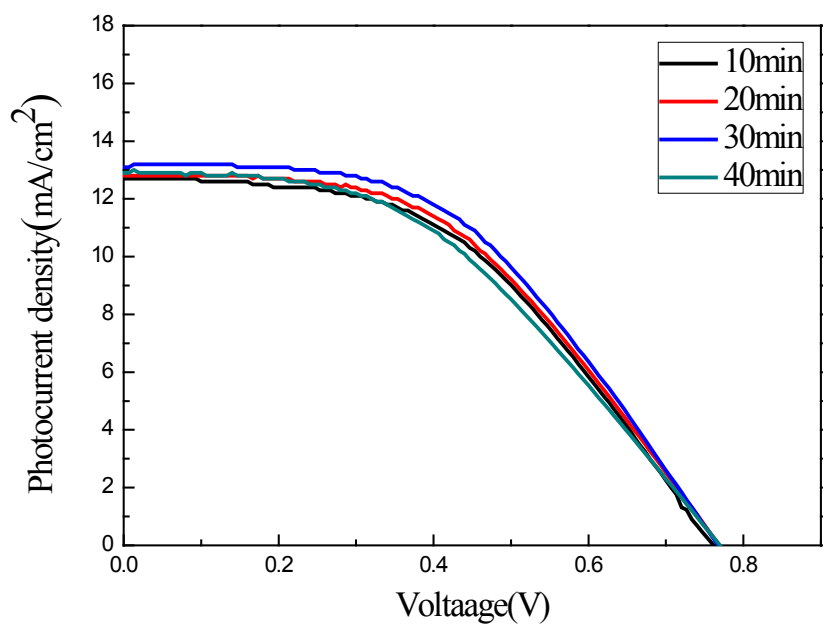

Fig. 9. The I-V curves of the DSSCs with the $\mathrm{TiO}_{2}$ working electrodes under different sintered times.

As we input all of the characteristics results into Origin software, the I-V curves figure was yield as Figure 9. The I-V curves indicates that different parameter has an effect on the photovoltaic characteristics of DSSCs. It also reveals that the photocurrent increases as the $\mathrm{TiO}_{2}$ sinter time increases. Based on Table 1, we also found that as the $\mathrm{TiO}_{2}$ sintered time increases, it improves $\mathrm{J}_{\mathrm{sc}}$ and FF. It explains the result of XRD in Figure 7. When $\mathrm{TiO}_{2}$ sintered at $450^{\circ} \mathrm{C}$ with enough time, anatase phase crystals and diffraction peak will be increased. In addition, $\mathrm{TiO}_{2}$ sintered for $30 \mathrm{~min}$ will yield the highest power conversion efficiency of $6.273 \%$.

\section{Conclusions}

In summary, we have demonstrated the influence of the $\mathrm{TiO}_{2}$ with different sintered time (10 min, $20 \mathrm{~min}, 30 \mathrm{~min}, 40 \mathrm{~min}$ ) of the working electrode on the DSSCs performance. It includes $\mathrm{V}_{\mathrm{oc}}, \mathrm{J}_{\mathrm{sc}}$, fill factor, and power conversion efficiency. SEM, XRD and I-V curve were conducted for the material analysis of the $\mathrm{TiO}_{2}$ photoanode. The photovoltaic characteristics were measured under AM 1.5 sunlight simulator. Different sintered time of $\mathrm{TiO}_{2}$ working electrode has an influence on the photovoltaic conversion efficiency. $\mathrm{TiO}_{2}$ sintered for 30 min will yield the highest power conversion efficiency of $6.273 \%$. 


\section{References}

1. Y.L. Lai, H.R. Hsu, Y. K. Lai, C.Y. Zeng, Y. H. Chou, N.K. Hsu, G.Y. Lung. ICPMMT (2017)

2. BP Statistical Review of World Energy June 2017

3. X. Yuan, X. Li, X. Zhang, Y. Li, L. Liu. Journal of Alloys and Compounds. 731(2018) 685-692

4. N. Huang, G. Li, Z. Xia, F. Zheng, H. Huang, W. L, C. Xiang, Y. Sun, P. Sun, X. Sun. Electrochimica Acta. 235 (2017) 182-190

5. J. Liu, Q. Tang, B. He. Journal of Power Sources. 268(2014) 52-62

6. M. Motlak, N. A. M. Barakat, A. G. El-Deen, A. M. Hamza, M. Obaid, O.B, Yang, M. S. Akhtar, K. A. Khalil. Applied Catalysis A : General 501 (2015) 41-47 